\title{
Problems and Countermeasures about the Deep Integration of Information Technology and Continuing Education under the New Normal
}

\author{
Wang Lixin \\ School of Media and Communication Technology \\ Liaocheng University \\ Liaocheng Shandong China \\ lxwang@lcu.edu.cn
}

\author{
$\mathrm{Fu}$ Chonggang \\ School of Chemistry and Chemical Engineering \\ Liaocheng University \\ Liaocheng Shandong China \\ cfgu@lcu.edu.cn
}

\begin{abstract}
The inherent characteristics of continuing education and the strategic demand of innovation driven under the new normal of economy condition put forward higher requirements for the integration of continuing education and information technology. The integration of information technology and education and teaching has always been the focus of attention of researchers. Starting from the characteristics of continuing education under the new normal, this paper analyzes the problems faced by continuing education under the new normal condition. This paper also describes the integration strategy of continuing education and information technology from the aspects of optimizing teaching models, enriching educational resources, improving teaching environment, improving the teaching ability of teachers and perfecting teaching evaluation.
\end{abstract}

Keywords-new normal, information technology, continuing education, deep integration

\section{INTRODUCTION}

Outline of National Education Medium and Long Term Development and Reform Plan (2010-2020) points out that:" We need to accelerate the development of continuing education, establish a sound mechanism for education and establish an open and flexible life-long education system". This shows that the state attaches importance to the development of continuing education. Opinions on Running Open University of the Ministry of Education emphasizes that" We need to adhere to deepen reform, innovate the develop models. And we need to renew the idea, accelerate organic integration of higher education, professional education, continuing education and distance-open education, strength the deep integration of information technology and education, innovate teaching environment and learning system, innovate school running models and the safeguard mechanism, create new high schools." We have put the deep integration of technology and education and teaching as a support for the development and innovation of continuing education. We basically reach a consensus on the deep integration of information technology and continuing education. "In the current stage of our country's college informatization, the primary application has been popularity used whether it is teaching information or management information. But the integration of innovative teaching models and management models are in the exploratory stage" [1]. The integration of information technology and education is the focus of many researchers and they have made a lot of research results [2-3]. Continuing education and ordinary higher education not only follow the common rules of education but also have their particularity, especially under the new normal, innovating teaching models and developing connotation construction of continuing education are facing many opportunities and challenges. Exploring the deep integration of information technology and continuing education under the new normal is the urgent need to ensure the healthy development of education.

\section{CONTINUING EDUCATION UNDER THE NEW NORMAL}

\section{A. Connotation of the new normal}

The term" the new normal" first appeared in the economic field to describe the macroeconomic state. The term was first proposed and interpreted in detail by general secretary $\mathrm{Xi}$ Jinping in henan in 2014, making the word "new normal" high frequency used to describe the current economic situation in China. After 30 years of rapid economic growth of in China, the basic model of economic development has changed dramatically. Great changes have taken place in China's economic fundamentals and it is necessary to look at Chinese economy with new views and new ways of thinking. First of all, China's economy has changed from high-speed growth to low-speed and medium-speed growth, from scale benefit to quality benefit. Second, economic structure has restructured and upgraded from the original development of main speed to optimize the economic structure. Third, the driving force of economic development has changed from factors and investment to innovation. Mapping to the field of education, 
Professor Gu Mingyuan pointed out that the development of China's education is facing three new normal, the first is to promote the fairness, the second is to make education more equitable, the third is Internet+education [4]. This three new normal are closely related to the integration of information technology and education. Making education more equitable not only need policy guarantee but also need technical support. Continuous improvement of information technology in Internet age provide technical support for educational equality. Simultaneously, Internet education has brought new possibilities for education approach, education environment and teacher-student relationship, which makes it possible to make high-quality continuing education. The innovation driving force that the normal operation of economic new normal needed is inseparable from the supply of talent in new normal education, while providing technical guarantees for the new normal education environment.

\section{B. Continuing education under the new normal}

Continuing education presents the characteristics that corresponding to the new normal in economy field whether in the scale of development, the speed of development or development power.

Speed and scale of development. Statistics from the National Bureau of Statistics showed that since 2010, the number of adult higher education school in China has gradually reduced from 365 in 2010 to 292 in 2015 . The school enrollments of china's colleges and universities of state academic education in 2011-2015 are 5.474962million, 6.264145 million, 6.531212million and 6.356352 million respectively, changed from slow growth to negative growth. The school enrollments of academic education is basically saturated. The number of non-degree education graduates sustained negative growth in 2012-2015. The statistics showed that it has been unsustainable for continuing education making a live by enrollment amount with the popularization of higher education. The Beijing university continuing education communication meeting held in January, 2017 decided to stop night university, network education, self-study examination and other types of continuing education enrollment since 2018 . Non-academic continuing education should aim at serving the national strategy and taking on the social responsibility. We need to improve the quality and level of continue education, explore and perfect the development model of integration of education and research. In College of continuing education of Shanghai Jiaotong University, the non-academic education tuition is equal to the academic education tuition for the first time in 2014. The College of Shanghai Jiaotong University decided to stop the enrollment of academic education. These phenomena indicate that the continuing education has completed its role as academic compensation and regular higher education supplement and it is facing the challenge of transformation from academic education to non-academic education and life-long education. When the object of continuing education is no longer for the purpose of academic, improving the quality of education to meet the need of society will become the first task of continuing education.

TABLE I. DEVELOPMENT OF CONTINUING EDUCATION IN 2011-2015

\begin{tabular}{|c|c|c|c|c|}
\hline \multirow{2}{*}{ Year } & The number & School enrollment of & The number of & The number of \\
& of adult higher & adult program & graduation of adult & graduation of adult \\
\hline 2011 & 353 & 547 & program \\
\hline 2012 & 348 & 583 & 191 & 6520 \\
\hline 2013 & 297 & 626 & 200 & 6316 \\
\hline 2014 & 295 & 653 & 221 & 6274 \\
\hline
\end{tabular}

The momentum of development. Continuing education is facing crisis and opportunities under the new normal. The development, transformation and upgrading of economic under the new normal are showing a great demand for the quantity and quality of talents training. The contradiction that the talents excess supply caused by the planned economy enrollment model while the demand side is a lack of talent resource will become the driving force of continuing education reform and development.
III. PROBLEMS CONTINUING EDUCATION IS FACING UNDER

\section{THE NEW NORMAL}

Under the new normal, the problems continuing education is facing are multifaceted. The external problems include the matriculate crisis caused by the double extrusion of disappearance of demographic dividend and popularization of higher education, the public's long-term lack of recognition of 
the value of continuing education, the weak policy support, etc. The internal problems include irrational structure of teachers. Continuing education and teaching tasks are usually held by higher education teachers, but the general higher education teachers lack enough understanding of the law of continuing education. The total performance is the lack of teachers which caused serious shortage of teaching resources, the serious disconnect between teaching content, training model and social demand, teaching quality cannot meet the need of enterprise innovation driven development strategy for talent.

The lack of educational resources. At present, online education is growing vigorously. There are a large number of web site platform. MOOC, video teaching resource develop rapidly. For the event that high school guidance teachers are paid 10000RMB per hour reported on the Internet in March 30, 2016, many people see the online education opportunities in Internet age. That also shows the lack of effective educational resource, otherwise there will not be too much user focus on individual teaching resources. In addition, throughout most of MOOC platform, the phenomenon of duplication of resource is general and this is also a manifestation of the lack of educational resources. Continuing education and secondary education are different in the nature of curriculum. The content of middle school curriculum is relatively concentrated and the efficiency of video online courses is high. Continuing education involves a large number of professionals and its teaching content is relatively dispersed. The task is more difficult to design and enrich education resources.

Teaching models are difficult to adapt to the innovation driven development strategy needs. Most of continuing education students attend class and learn by themselves when not working, making the teaching time and communication between teachers and students limited. In addition, because of the school condition, many courses especially experimental science and engineering practice content is weakened even canceled. This affect the training quality seriously and it is also the reason for public have different cognition on the value of continuing education and normal higher education.

Didn't make full use of information technology and didn't give full play to advantages of information in teaching activities. Information and education teaching activities are" two pieces of skin". Even though most of education teaching activities have adopted information technology on different level, however, some of them are using it in inappropriate time, some of them are using them on inappropriate way, making the information technology means interfere with the teaching activities on different level when it is used to assist teaching. The reason, one is the teachers is not skilled at information technology means, another is that the level of information has not yet reach the level of the teaching activities of the silent state, therefore energy of students and teachers is consumed in the teaching activity and they cannot go into teaching activities and be distracted.

Whether the construction of educational resources or the optimization of teaching mode cannot be separated from the support of information technology. One of the problems faced by continuing education under the new normal is the deep integration with information technology.

\section{STRATEGIES OF THE DEEP INTEGRATION OF}

\section{INFORMATION TECHNOLOGY AND CONTINUING EDUCATION}

Many scholars have focused on the relationship between information technology and education. From the initial" information technology as a tool for education teaching auxiliary", later, "integration of information technology and curriculum", now" the integration of information technology and teaching", people's understanding of the relationship between information technology and teaching activities is becoming more and more profound. The characteristics of the deep integration of information technology and continuing education should be "have like didn't have, didn't have like have" in the teaching activities. "Have like didn't have" is that education and teaching activities by information technology means should be natural as writing naturally with chalk in traditional way of teaching. "Didn't have like have" is that information technology environment has been integrated with the natural teaching environment, and it provides environment support for teaching activities but we cannot feel it. It is not an overnight process to achieve this level and we should proceed from the following aspects.

\section{A. Use information technology to optimize and enrich education resources.}

Continuing education under the new normal will be based on connotative development. High-quality education resources is the guarantee of attracting continuing education students and training quality talents. The spatial and temporal characteristics of the objects of continuing education determines that their demand for demand for educational resources is different from the ordinary higher education. They have fewer opportunities to face to face teaching and need higher quality education resources more to ensure independent learning. Using information technology to strengthen the construction of content of the network platform, enrich the network teaching resources to make up for the gap between continuing education and higher education, meet the need of continuing education students.

\section{B. Use information technology to innovate continuing education models.}

Previous continuing education is limited by objective conditions. Apart from face to face teaching time, students rely on self-learning. There are rare even no opportunities for teachers and students to communicate. Information technology environment provides opportunities for both sides of continuing education to communicate. Network platform and instant communication tools provide a new teaching environment for continuing education [5]. How to make full use of this favorable condition to innovate the teaching models of continuing education is an important aspect of the integration of information technology and continuing education. 


\section{Improve the teaching effect by using information technology.}

Under the new normal, the teaching content of continuing education need to update and optimize. Traditional teaching methods cannot achieve the desired teaching effect and information technology can help. For example, the working principle of the engine, we can use animation technology to show its work process and internal scene vividly, get the effect that any language or text description cannot achieve. Another example, hole imaging physics experiment, the traditional teaching methods need to be equipped with a variety of equipment, but with the use of VR technology, we can do the interaction of the real environment and virtual with only a computer with a normal camera or just a tablet or mobile (take the camera). The interaction between the operator and the experimental equipment is completely natural, which is exactly the same as the traditional experiment [6].

\section{Use information technology to improve teaching ability of teachers.}

Teachers are not only interpreters of knowledge but also should be the organizers and participants in teaching activities. In information age, teachers especially continuing education teachers should not only have rich professional knowledge, but also should master the teaching rules and teaching skills under information technology environment. As previously mentioned, most of the continuing education teachers is held by college teachers and they are difficult to control the continuing education teaching rules, especially the education and teaching activities in information technology environment. Improving the teaching ability under the information technology environment is another manifestation of the further integration of continuing education and information technology.

\section{E. Using information technology to improve the evaluation mechanism of continuing education.}

Evaluation is the basis for the recognition and encouragement of Continuing Education. A scientific evaluation mechanism is the guarantee for the healthy development of continuing education. The information technology environment provides scientific basis and data resources for scientific evaluation of continuing education. For the traditional education evaluation, one is the method proceed through classroom observation and comment this subjective way which rely on experience and observation, it requires a high degree of evaluation and evaluation efficiency and science are limited. The second is it rely on education and teaching static data such as test scores as evaluation indicators, due to the traditional data collection efficiency is low and the data coverage is narrow, the evaluation function is limited and the feedback guidance function is weak. It provides convenience for the dynamic data acquisition in the teaching process, making the whole process of the teaching process controllable and provide timely and objective evaluation basis for improving the teaching quality

\section{V.CONCLUSION}

Under the economic new normal conditions, education is facing the demand of reforming teaching content, innovating teaching models and improving the quality of teaching. Living environment is squeezed by ordinary higher school, continuing education's tasks are more arduous. The deep integration of information technology and continuing education provides guarantee for the continuing education connotation development. To achieve this goal, we should start with various elements of specific teaching practice, optimize the teaching resources by using information technology, innovate the teaching mode, improve the teaching effect, improve the teaching ability of teachers' information, and improve the evaluation mechanism.

\section{ACKNOWLEDGEMENT}

This paper is supported by the project" The Challenge and Opportunity of Continuing Education under the New Normal Condition and the Deep Integration of Information Technology" The project is held by Liaocheng University continuing education department and the project number is ldcj201511. Hereby acknowledge.

\section{REFERENCES}

[1] Jiang Dongxing, Meng Hai, Kong Fanshi, et al., "The development of education informatization and Countermeasures of "13th Five-Year", The Chinese Journal of ICT in Education, 2016(01), pp14-18

[2] Hu Zhinong, Su Ping, "Analysis on the Strategy for Deepening the Integration of Information Technology and Non-Diploma Education”, Journal of Nanjing Radio \& TV University, 2013(1), pp4-7

[3] Yang Zongkai, Yang Hao, Wu Di, "On the In-depth Integration of ICT with Present Education”, Educational Research, 2014(03), pp88-95

[4] Gu Mingyuan, "China's education development faces three new normal", http://learning.sohu.com/20151020/n423698127.shtml

[5] Wang Zhengqing, Tang Xiaoling, " Study on Impetus and Approaches of Deep Integration of Information Technology and Instruction", e-Education Research, 2017(01) pp94-100

[6] Cai Su, Zhang Han, Xue Xiaoru, et al. , "Review on Applications of AR in Education in China", China Educational Technology, 2017(03), pp1-9,30 